\section{Interpersonal Psychotherapy Efficacy in Different Clinical Settings}

\begin{abstract}
Interpersonal therapy is an effective brief and limited therapy originally developed for major depression disorder but nowadays also highly effective in other psychiatric disorders $[1,2]$. This therapy uses the biopsychosocial model as a tool to approach depression and relieve the symptoms by focusing the intervention in the present and on the interpersonal problems behind it [3]. The interpersonal problems are divided in three main problem areas: grief and loss, interpersonal disputes and role transition. These are the focus of the intervention after being identified by the therapist and the patient, at the end of the assessment and initial phase, which is the first of a three phase psychotherapeutic process. The three phases of the therapy take normally 12 to 20 sessions, three-to-four month period. The initial phase incorporates assessment, interpersonal inventory, formulation and treatment agreement. The middle phase includes patient communication style analysis and focus on the agreed problem area. When the symptoms have reduced or resolved, usually connected with the resolution of the problem area, the therapy enters the third and final phase, when it is important to review what happened since the beginning of the therapy, focusing in the changes made by the patient, namely self awareness, situation analysis capacity communication style, symptom decrease and the capacity to signalize future situations that can trigger new depressive symptoms and which skills were more adapted. Originally the therapy did not have included following sessions but nowadays there are some authors that preconize maintenance sessions $[4,5]$ and a not ending therapy giving the opportunity to the patient to return whenever he want [6].
\end{abstract}

The literature of clinical practice of interpersonal therapy in Portugal is very scarce, even knowing that the therapy has shown being highly effective, similar to cognitive behaviour therapies in major depression disorder. The only known portuguese study until date is from Carlos Gois [7]. Given this lack of research, we pretend to evaluate the efficacy of the interpersonal therapy in a portuguese major depression disorder population in both public and private settings.

Our aim for this research is to see and compare the results of IPT in two different settings. Participants: 64 patients that seeked for treatment in both settings and after being diagnosticated with major depression disorder, they were offered a full interpersonal therapy intervention. Method: The interpersonal therapy basic model was the one of Scott Stuart [6] and we collect demographic data from all the patients and used two clinical scales: Beck depression inventory and adult attachment scale - R. Results: They show that interpersonal therapy was equally effective in both settings. Conclusion: Interpersonal therapy is effective in the treatment of a portuguese population with major depression disorder, giving more strength for is spreading through all the mental health workers.

\section{Introduction}

The Portuguese Psychology Association estimate that 19.3\% of the portuguese population will suffer of any type of depressive disorder during their lifespan, $6.8 \%$ annual prevalence of Major depression Disorder (MDD) in the portuguese population and $7.9 \%$ for any affective disorders (www.dgs.pt). In most cases they will be
Journal of

Neurology and Psychology

\section{Nuno Carrilho ${ }^{1}$, Ivandro Soares Monteiro ${ }^{2 *}$, Esmeralda Vaz ${ }^{3}$, Carla Vicente ${ }^{1}$, Ana Martins ${ }^{1}$, Ana Catarina Silva ${ }^{1}$ and Raquel Santos ${ }^{1}$}

${ }^{\prime}$ Baixo Vouga Hospital Center, BVHC, EPE, Portugal ${ }^{2}$ ORASI Institute, Rua Arq. Marques da Silva, Portugal ${ }^{3}$ EME Health Clinic, Portugal

\section{${ }^{*}$ Address for Correspondence}

Ivandro Soares Monteiro, Ph.D, M.Sc, ORASI Institute, Rua Arq. Marques da Silva, n. $285,1^{\circ} \mathrm{C}, 4150-484$ Porto, Portugal, Tel: (+351) 226066942/ 916066932; E mail: ismonteiro@gmail.com

Submission: 11 August 2015

Accepted: 06 October 2015

Published: 12 October 2015

Copyright: (๑) 2015 Carrilho N, et al. This is an open access article distributed under the Creative Commons Attribution License, which permits unrestricted use, distribution, and reproduction in any medium, provided the original work is properly cited.

Reviewed \& Approved by: Dr. Øyvind Kvello, Associate Professor of Psychology, The Center for Child and Adolescent Mental Health, Eastern and Southern Norway

prescribed with medication rather than psychotherapy. There are several reasons for this to happen: it is easier to have access in the public health system to a General Practice or even a psychiatrist than a psychological treatment, besides the fact that there are few well trained - because it is not mandatory - few psychotherapists are practising in the mental health system and the ones on the system, do not have the capacity for all the demand. Depression is a public health problem and should be addressed as such [8]. Concerning the type of psychotherapies, the most spread are Cognitive Behavioural Therapy (CBT), psychodynamic therapies and systemic therapies. Usually Interpersonal Psychotherapy (IPT) is not taught in the psychology degree, or seldom, and also in the psychiatric internship even when the data, experimental and clinical, say that IPT is an effective brief psychotherapy, originally built for MDD in the seventies and showed equal efficacy as CBT and Imipramine (antidepressant) in the eighties. During the decades IPT have shown to be effective in other psychiatric pathologies like dysthymia, bulimia, Post Traumatic Stress Disorder and so on $[1,2,6]$.

IPT is a psychotherapy based in the biopsychosocial model where the interpersonal relations are seen as primordial way to improve patient symptoms, mainly connected to the actual interpersonal problems [3]. As the name itself expresses, the interpersonal relations and the way the patients communicate their feelings, distress, ask for help or give them are very important in the patient evaluation and their connection with the symptoms and their improvements. There are three main theories that influence IPT model, the attachment theory, interpersonal theory and social theory, for which they are all connected. The attachment style will influence the way the persons communicate with others and their needs, which determine their communication style and the way they interact with the others, create relations and what is the impact on their social network. Other influences also present in this therapy, like psychodynamic 
Citation: Carrilho N, Monteiro IS, Vicente C, Vaz E, Martins A, et al. Interpersonal Psychotherapy Efficacy in Different Clinical Settings. J Neurol Psychol. 2015;3(2): 5 .

theories, but they are not the focus of the intervention and only used to help the therapist to analyse the patient in their therapeutic relation. As in all the others psychotherapies, the IPT therapist has a special care in creating a collaborative setting with the patient, in a consistent therapeutic process, validating and accepting the patient, giving a secure place for self disclosure and finally motivating him to change [9]. Another focus, as in all other therapies, is the therapeutic alliance, their maintenance and increasing during the intervention, because they are a good predictor of the permanence of the patient in the therapeutic process and with a positive influence in the patient $[10,11]$.

\section{IPT intervention has 3 phases.}

The initial phase usually takes two to three sessions and incorporates evaluation, communication and attachment analysis, interpersonal inventory and ends with interpersonal formulation and an agreed problem area.

The second and middle phase normally takes 4 to 12 sessions and is where the work with the chosen problem area takes place. There are three main problem areas, (1) Grief and Loss, which is when someone close dies or loses someone important (divorce) or losses some of their functions caused by an accident or severe disease (disabling pathologies like car accidents with the loss of some member function). What is important to work in these cases is the therapeutic relation, the denial of the loss, and help the patient to deal with the new situation, the losses and see what they still have and can do to improve their present situation and use them in their interpersonal relationships. Other problem area is (2) interpersonal disputes, which occurs when the patient have conflicts with partners, family, friends, colleagues, boss and others. Usually they have different opinions and the patient do not know how to resolve them, identifying the relationship as import but being unsatisfied with the outcome. In this situation we help the patient to better analyse the situation, recognize the nature of the problem, signalize what they pretend of the relation, redefine the relationship and strategies more suitable for the goals of the patient and achieve, again, a stable emotional state. Usually, they had previous similar reactions for the same problems, being very important to signalize it and prevent future relapses. The last problem area is (3) role transition, which is a common situation in anyone life's but sometimes can be interpreted as a dead end situation with a huge loss associated. Examples during our life's of role transitions are the transition to adulthood, entering university, new job, being a father/mother, new residency and so on, that imply a change in the previous role of the person and can bring changes that can be considered as more negative than positive. In this situations the person can develop depressive symptoms, can not cope with the new situation and start to compare the old with the new role, seeing is present role only as a negative one. The work of IPT in this problem area is to help the client to analyse the reasons for the transition, what have made the patient choose it (or not), see what they really have lost, what they still have and what have became better in their new role. This process enables a better self confidence of the patient and the necessary support for them to start doing plans and choose different strategies and responsibilities to connect with the new role.

The third and end phase normally takes place in one or two sessions and is import to review all the process, talk about the ending and the emotions that come with them and prevent future situations that probably will trigger new depression events $[3,6]$. Not everyone advocates follow up sessions, but new literature with experimental and clinical basis have integrated follow up sessions in some clinical cases to prevent future depression episodes [4-6].

The aim of our clinical research is to find if IPT is or is not effective in the portuguese depressed population, and if so, which differences are evident in the effectiveness between public and private practice. The reason for these two goals came from the initial idea of investigation the effectiveness of IPT in Portugal and also because the two main authors, both clinical experienced, work in two totally different settings and the patients came naturally from theses two different healing environments. Given this junction we decided to see if any of these healing environments were better than the other and if there was differences in the patient's characteristics.

\section{Material and Methods}

\section{Patients}

The patients included in this study where the ones diagnosed with MDD by their therapist and afterwards were referred to IPT psychotherapy. This was not a clinical trial (a new intervention proposal) but our daily clinical practice in both settings. 64 cases where referred, being 30 from the public practice and 34 from the private practice. There was no exclusion criterion to be accepted into this study. Being with anti-depressive or any other psychotropic drug was accepted in our intervention.

\section{Clinical assessment}

Sociodemographic assessment was made for all the patients. A complete medical and psychiatric history was made and also assessed their medication.

\section{Psychometric assessment}

Beck Depression Inventory (BDI) [12]: Validated for a portuguese population by Vaz Serra and Pio Abreu [13]. This is a 21 questions scale, and each answer being scored on a scale value of 0 to 3 . Higher total score indicates more severe depressive symptoms. The standardized cutoffs are 0-13: minimal depression; 14-19: mild depression; 20-28: moderate depression; and 29-63: severe depression.

The Adult Attachment Scale (AAS-R) [14]: The portuguese version of the AAS-R [14] was used to detect the three attachment dimensions, secure, anxious and trusting others (reverse avoidant) previously obtained by a factor analysis procedure and explaining the $46.62 \%$ in variance. In the validation procedure, reliability assessed by Cronbach's coefficient a provided $0.84,0.67$ and 0.54 to secure, anxious and trusting others' attachment sub-scales, respectively. All sub-scale scores range from 6 to 30 [15].

The scale consists of 18 items scored on a 5 point likert-type scale. It measures adult attachment styles named "secure", "preoccupied", "fearful", "dismissing" and "not classified".

No other psychometric assessments were used in both settings.

\section{Study design}

The patients were evaluated at baseline and at the end of treatment. 
Citation: Carrilho N, Monteiro IS, Vicente C, Vaz E, Martins A, et al. Interpersonal Psychotherapy Efficacy in Different Clinical Settings. J Neurol Psychol. 2015;3(2): 5 .

ISSN: $2332-3469$

IPT was delivered on a weekly basis between 6 to 32 sessions depending entirely on the therapist evaluation. All the psychotherapeutic interventions add a basic structure of the IPT treatment [6].

\section{Statistical analysis}

To compare groups with nominal variable, we employed the ChiSquared test.

In univariate analysis and in order to detect the differences at baseline between continuous variables, we used unpaired t-tests or the Mann-Whitney $U$ test, after checking for normal distribution, with the Shapiro-Wilk test and K-S test.

Repeated measures pair t-test were conducted to examine the variance between continuous variables at the baseline and at the ending of the intervention.

Repeated measures McNemar-Bowker Test Symmetry were conducted to examine the variance between nominal variables at the baseline and at the ending of the intervention.

SPSS v.22 for Mac was used for all evaluations. The significance level was accepted as $\mathrm{p}<0.05$ (two-sided) in all analyses.

\section{Results}

\section{Participant's characteristics}

They were 64, 30 from the public setting and 34 from the private practice. We found no differences between both settings concerning in gender and age. $73.4 \%$ were female $\left(\mathrm{x}^{2}(1, \mathrm{n}=64)=0.694, \mathrm{p}=0.405\right.$, phi $=0.14)$ and $63.6 \%$ had a age between 26 and 45 years old ( $\mathrm{p}=0.356$, Mann-Whitney). They had no difference in their family $\left(\mathrm{x}^{2}(\mathrm{n}=64)=11.754, \mathrm{p}=0.124\right.$, $\left.\mathrm{phi}=0.429\right)$ and personal $\left(\mathrm{x}^{2}(8, \mathrm{n}=64)\right.$ $=12.662, \mathrm{p}=0.405$, phi $=0.445)$ psychiatric background. $20 \%$ had a family member with an affective disorder and $36 \%$ of the participants with, at least, one previous episode of an affective disorder before this treatment.

5 of the participants had no BDI criteria for depression (7.9\%), but were accepted in the intervention. In all the other sociodemographic characteristics both participants settings were different (Table 1).

\section{Public setting}

They came more from a rural area $(56.7 \%)$, were more divorced and single, lower education degree (only $20 \%$ more students with an university degree), more unemployment (20\%) but also students (20\%). They had more previous psychiatric follow up (66.7\%) and came with more medication prescribed (86.7\%). The most common medication was antidepressive, seen in $86 \%$ of the cases.

\section{Private setting}

They all came from an urban area, had more stable relations (70.6\% married or together with someone), higher education degree (52.9\% with an university degree), a more stable work situation (94.1\% employed), had less previous psychiatric follow up (44.2\%) and medication (41.2\%).

\section{Clinical data}

Number of sessions were significantly different between public and private settings. (Mann-Whitney Test: Private $(\mathrm{Md}=8, \mathrm{n}=34)$,
Table 1: Sociodemographic characteristics of both public and private participants' settings

\begin{tabular}{|c|c|c|}
\hline Results & Public & Private \\
\hline Sex & \multicolumn{2}{|c|}{$\left(x^{2}(1, n=64)=0.694, p=0.405, p h i=0.14\right)$} \\
\hline Female & $24(80 \%)$ & $23(67.6 \%)$ \\
\hline Male & $6(20 \%)$ & $11(32.4 \%)$ \\
\hline Age & \multicolumn{2}{|c|}{ ( $p=0,356$, Mann-Whitney) } \\
\hline$<25$ & $4(13,3 \%)$ & $3(8.8 \%)$ \\
\hline $26-35$ & $9(30 \%)$ & $12(35.6 \%)$ \\
\hline $36-45$ & $11(36.7 \%)$ & $10(29.4 \%)$ \\
\hline 46-55 & $5(16.7 \%)$ & $7(20.6 \%)$ \\
\hline$>56$ & $1(3.3 \%)$ & $2(5.9 \%)$ \\
\hline Living area & \multicolumn{2}{|c|}{$\left(x^{2}(2, n=64)=26.235, p=0.0, p h i=0.64\right)$} \\
\hline Urban & $13(43.3 \%)$ & $34(100 \%)$ \\
\hline Village & $14(46.7 \%)$ & $0(0 \%)$ \\
\hline Rural & $3(10 \%)$ & $0(0 \%)$ \\
\hline Working Status & \multicolumn{2}{|c|}{$\left(x^{2}(3, n=64)=14.297, p=0.003, p h i=0.47\right)$} \\
\hline Student & $2(20 \%)$ & $0(0 \%)$ \\
\hline Employed & $18(60 \%)$ & $32(94.1 \%)$ \\
\hline Unemployed & $6(20 \%)$ & $1(2.9 \%)$ \\
\hline Retired & $0(0 \%)$ & $1(2.9 \%)$ \\
\hline Education Status & \multicolumn{2}{|c|}{$\left(x^{2}(5, n=64)=11.911, p=0.036, p h i=0.431\right)$} \\
\hline Primary & $1(3.3 \%)$ & $1(2.9 \%)$ \\
\hline Basic & $5(16.7 \%)$ & $3(8.8 \%)$ \\
\hline Secondary & $6(20 \%)$ & $1(2.9 \%)$ \\
\hline High School & $12(40 \%)$ & $11(32.4 \%)$ \\
\hline University & $6(20 \%)$ & $18(52.9 \%)$ \\
\hline Marital Status & \multicolumn{2}{|c|}{$\left(x^{2}(3, n=64)=15.648, p=0.01, p h i=0.49\right)$} \\
\hline Single & $11(36.7 \%)$ & $8(23.5 \%)$ \\
\hline Married & $8(26.7 \%)$ & $24(70.6 \%)$ \\
\hline Divorced & $10(33.3 \%)$ & $1(2.9 \%)$ \\
\hline Widow & $1(3.3 \%)$ & $1(2.9 \%)$ \\
\hline
\end{tabular}

public ( $\mathrm{Md}=12.5, \mathrm{n}=30$ ), $\mathrm{U}=237.5, \mathrm{z}=-3.686, \mathrm{p}=.0, \mathrm{r}=0.46$ (median effect size). Their mean was 23.44 ( $\mathrm{SD}=6.234)$. The public setting needed more sessions than the private practice (Table 2).

They showed no difference in their baseline BDI answers (MannWhitney Test: Private $(\mathrm{Md}=23, \mathrm{n}=34)$, public $(\mathrm{Md}=25, \mathrm{n}=30), \mathrm{U}=$ $435, \mathrm{z}=-0.8, \mathrm{p}=0.422, \mathrm{r}=0.1$ (small effect size). Their mean was 23.44 $(\mathrm{SD}=6.234)$.

They showed no difference in their end intervention BDI answers (Mann-Whitney Test: Private $(\mathrm{Md}=10, \mathrm{n}=34)$, public $(\mathrm{Md}=9.5$, $\mathrm{n}=30$ ), $\mathrm{U}=388, \mathrm{z}=-0.807, \mathrm{p}=0.420, \mathrm{r}=0.1$ (small effect size). Their mean was $11.80(\mathrm{SD}=7.854)$.

$\mathrm{BDI}$ at baseline and at the end of the intervention decreased significantly from mean $23.68(\mathrm{SD}=5.871)$ to 11.95 ( $\mathrm{SD}=7.835)$ pair $\mathrm{t}$-test $(\mathrm{M}=23.68 \mathrm{SD}=5.871), \mathrm{t}(59)=12.995, \mathrm{p}=0$ (two tailed). The mean reduction was of 11.729 with $95 \%$ confidence in an interval from 9.922-13.535. Eta square of 0.74 which is a big effect size. 
Citation: Carrilho N, Monteiro IS, Vicente C, Vaz E, Martins A, et al. Interpersonal Psychotherapy Efficacy in Different Clinical Settings. J Neurol Psychol. 2015;3(2): 5 .

\section{ISSN: 2332-3469}

The public and the private settings showed different initial AAS-R (attachment) results. The public setting showed more secure attachments and non classified, instead, the private practice showed more preoccupied and fearful attachments $\left(\mathrm{x}^{2}(4, \mathrm{n}=64)=14.894, \mathrm{p}=\right.$ 0.005, phi $=0.482$ ).

At the end of the intervention, the results in the AAS-R between the two populations maintained their difference $\left(\mathrm{x}^{2}(4, \mathrm{n}=59)=10.036\right.$, $\mathrm{p}=0.04$, phi $=0.412$ ). There was still more secure and not classified attachment participants in the public setting (Table 3 ).

AAS- $\mathrm{R}$ answers changed in both setting between the baseline and at the end of the intervention (McNemar-Bowker Test $(8, n=59)=20$, $\mathrm{p}=0.01$, phi $=1.053$ (big size effect)) (Table 4).

\section{Discussion and Conclusion}

This preliminary study concerning the effectiveness of IPT in a

Table 2: Clinical data about the two populations.

\begin{tabular}{|c|c|c|}
\hline Results & Public & Private \\
\hline Sex & \multicolumn{2}{|c|}{$\left(x^{2}(1, n=64)=0.694, p=0.405, p h i=0.14\right)$} \\
\hline Female & $24(80 \%)$ & $23(67.6 \%)$ \\
\hline Male & $6(20 \%)$ & $11(32.4 \%)$ \\
\hline Age & \multicolumn{2}{|c|}{$(p=0,356$, Mann-Whitney) } \\
\hline$<25$ & $4(13.3 \%)$ & $3(8.8 \%)$ \\
\hline $26-35$ & $9(30 \%)$ & $12(35.6 \%)$ \\
\hline $36-45$ & $11(36.7 \%)$ & $10(29.4 \%)$ \\
\hline 46-55 & $5(16.7 \%)$ & $7(20.6 \%)$ \\
\hline$>56$ & $1(3.3 \%)$ & $2(5.9 \%)$ \\
\hline $\begin{array}{l}\text { Family Psychiatric } \\
\text { background }\end{array}$ & \multicolumn{2}{|c|}{$\left(x^{2}(n=64)=11.754, p=0.124, p h i=0.429\right)$} \\
\hline Affective disorder & $3(10 \%)$ & $10(29.4 \%)$ \\
\hline Anxiety disorder & $2(6.7 \%)$ & $1(2.9 \%)$ \\
\hline Suicide attempt & $1(3.3 \%)$ & $1(2.9 \%)$ \\
\hline Psychosis & $0(0 \%)$ & $1(2.9 \%)$ \\
\hline Drug abuse & $2(6.7 \%)$ & $1(2.9 \%)$ \\
\hline None & $24(80 \%)$ & $14(41.2 \%)$ \\
\hline $\begin{array}{l}\text { Personal Psychiatric } \\
\text { History }\end{array}$ & \multicolumn{2}{|c|}{$\left(x^{2}(8, n=64)=12.662, p=0.405, p h i=0.445\right)$} \\
\hline Affective disorder & $13(43.3 \%)$ & $10(29.4 \%)$ \\
\hline Anxiety disorder & $1(3.3 \%)$ & $4(11.8 \%)$ \\
\hline Adjustment Disorder & $2(6.6 \%)$ & $0(0 \%)$ \\
\hline Personality disorder & $3(10 \%)$ & $0(0 \%)$ \\
\hline none & $11(36.9 \%)$ & $20(58.8 \%)$ \\
\hline Previous Followup & \multicolumn{2}{|c|}{$\left(x^{2}(7, n=64)=38.632, p=0.0, p h i=0.78\right)$} \\
\hline Active Outpatient & $10(59 \%)$ & $2(5.9 \%)$ \\
\hline Abandoned Outpatient & $1(3.3 \%)$ & $2(5.9 \%)$ \\
\hline Release Outpatient & $3(10 \%)$ & $11(32.3 \%)$ \\
\hline None & $5(16.7 \%)$ & $19(55.9 \%)$ \\
\hline Previous Medication & \multicolumn{2}{|c|}{$\left(x^{2}(8, n=64)=36.448, p=0.0, p h i=0.75\right)$} \\
\hline None & $4(13.3 \%)$ & $14(41.2 \%)$ \\
\hline Psychiatric medication & $26(86.7 \%)$ & $20(58.8 \%)$ \\
\hline
\end{tabular}

Table 3: Adult Attachment Scale - $\mathrm{R}$ answers between both public and private participant's setting were different.

\begin{tabular}{|l|l|l|}
\hline AAS-R & Public & Private \\
\hline Baseline & $\left(\mathrm{x}^{2}(4, \mathrm{n}=64)=14.894, \mathrm{p}=0.005, \mathrm{phi}=0.482\right)$ \\
\hline Secure & $6(20 \%)$ & $4(11.8 \%)$ \\
\hline Preoccupied & $5(16.7 \%)$ & $13(38.2 \%)$ \\
\hline Fearful & $8(26.7 \%)$ & $15(44.1 \%)$ \\
\hline Dismissing & $2(6.7 \%)$ & $2(5.9 \%)$ \\
\hline Not classified & $9(30 \%)$ & $0(0 \%)$ \\
\hline End Treatment & $\left(\mathrm{x}^{2}(4, \mathrm{n}=59)=10.036, \mathrm{p}=0.04, \mathrm{phi}=0.412\right)$ \\
\hline Secure & $11(36.7 \%)$ & $8(23.5 \%)$ \\
\hline Preoccupied & $4(13.3 \%)$ & $15(44.1 \%)$ \\
\hline Fearful & $4(13.3 \%)$ & $8(23.5 \%)$ \\
\hline Dismissing & $1(3.3 \%)$ & $2(5.9 \%)$ \\
\hline Not classified & $5(16.7 \%)$ & $1(2.9 \%)$ \\
\hline
\end{tabular}

Table 4: Adult Attachment Scale - $\mathrm{R}$ answers changed between the baseline and at the end of the intervention.

\begin{tabular}{|l|l|c|}
\hline \multicolumn{1}{|c|}{ AAS-R } & Baseline & \multicolumn{1}{c|}{ End Treatment } \\
\hline McNemar-Bower test & $\left(\mathrm{x}^{2}(4, \mathrm{n}=64)=14.894, \mathrm{p}=0.005, \mathrm{phi}=0.482\right)$ \\
\hline Secure & $10(15.6 \%)$ & $19(32.2 \%)$ \\
\hline Preoccupied & $18(28.1 \%)$ & $19(32.2 \%)$ \\
\hline Fearful & $23(35.9 \%)$ & $12(18.8 \%)$ \\
\hline Dismissing & $4(6.3 \%)$ & $3(4.7 \%)$ \\
\hline Not classified & $9(14.1 \%)$ & $6(9.4 \%)$ \\
\hline
\end{tabular}

MDD portuguese population and in two different settings, showed that the gender, age, family and personal psychiatric history and the baseline BDI was not different between public and private patients. The two populations were mainly female patients with 26 to 45 years old, $20 \%$ had past family history of affective disorder and $36 \%$ had one previously, at least, episode of affective disorder.

The results also demonstrate that $92.1 \%$ of the cases had, psychometrically, a depression (BDI higher than 14) and meaning that almost all were well referred to an intervention aimed to depression.

Besides this similarities, as we could previous expect, the two settings, public and private, had sociodemographic differences. The public population was more from rural areas, had less education, worst work situation, but also more students, came to the intervention with more medication and had higher previous psychiatric follow up.

What was quite surprising was the attachment style differences between the two populations and given the worst personal psychiatric history in the public setting. We should expect a more dysfunctional attachment style, but the public participants showed a more secure attachment style, while the private patients showed higher preoccupied, fearful and dismissing attachment styles. Probably, these differences are explained, in our clinical opinion, by the different reasons for treatment seeking. In our perspective, patients from private practice have a significant higher consciousness of their problems and, therefore, higher motivation to seek treatment. Probably connected to their attachment profile, more demanding and with a higher inner capacity to ask for help (they are the ones that have to search for a solution - more proactive). Instead, the public patient 
Citation: Carrilho N, Monteiro IS, Vicente C, Vaz E, Martins A, et al. Interpersonal Psychotherapy Efficacy in Different Clinical Settings. J Neurol Psychol. 2015;3(2): 5 .

is identified by the doctor who refers these patients for treatment, maybe showing a lower inner capacity to ask for help. More research should analyse this results and hypothesis.

Our initial hypothesis, when we gathered data from this two different population, was to so see if there were different outcomes. Above all variables and comparisons, we made evident that in both settings IPT is a strutured and scientific based successful psychotherapy, in which, even with lower education patients, different backgrounds, attachment styles and treatment payments (e.g., free in the public hospital) the efficacy is evident.

Besides this, we found changes in the attachment style, not a focus from this therapy, but maybe an indirect and parallel consequence from this intervention. Another reason for this attachment changes, because normally there is the idea that attachment styles are very difficult to change, is that the depression symptoms interfere with the initial attachment evaluation or therapy induced changes in the attachment style. More research, definitely, is needed in this particular field.

Another interesting finding is that the private practice needed less sessions to finish the intervention, compared with the public practice. There are a lot of possible reasons: because in private practice they have to pay and are more motivated; because the public practice have worst cases (they have more personal psychiatric history); because of their different attachment styles. More research is needed to confirm these possibilities.

The last curious result is the maintenance of efficacy of the IPT therapy in cases with more than 20 sessions, as it did occur in the public practice, even tough the IPT manual advocates less than 20 sessions to prevent a change of focus from "now and here" (problem area) to a more transference and countertransference focus therapy (which is not the aim of IPT).

We also assume a number of limitations to our study. It is only a preliminary study that lacks a control group, a more uniformed manual treatment (with the same sessions, duration and so on), we have limited sample and we should, at least, have more psychometrics scales. In future research, paired samples between public and private settings would increase the evidence and main reasons for the obtained results, in order to confirm them or bring new conclusions.

The stronger contribution from this study is the evidence that IPT seems to work as well in the portuguese MDD population (a south european population, and considering the culture, social life and religion (mostly catholic)) and in different settings. The interpersonal psychotherapy approach seems a very promissory therapy that more health professionals should use. This data should stimulate more and better studies about its effectiveness in MDD (see [7]), as also in other psychiatric disorders where they have shown good results. Replications of this research are recommended in portuguese population, with bigger samples and settings. This Psychotherapy should also be spread in early graduations of health professionals nationally, since it has become one of the best and recommended psychotherapies for depression in adults [16-18], as well or even better that CBT [19] and it is included as a guideline evidence-based psychotherapy by american psychiatric association (APA) $[20,21]$.

\section{References}

1. de Mello MF (2004) Terapia Interpessoal: um modelo breve e focal. Rev Bras Psiquiatr 26: 124-130.

2. Wilfey DE, MacKenzie KR, Welch RR, Ayres VE, Weissman MM (2000) Interpersonal psychotherapy for group. Basic Behavioral Science.

3. Carvalho RA, Pupo MC, Mello MF (2011) Interpersonal therapy: theory, training and clinical practice in a service of research and treatment on violence. Rev Bras Psicoter 13: 14-25.

4. Markowitz J, Swartz H (2007) Case Formulation in Interpersonal Psychotherapy of depression. In: Eels TD (Ed) Handbook of psychotherapy case formulation, Second Edition. New York, Guilford 2: 221-448.

5. Bellino S, Rinaldi C, Boggeto F (2010) Adaptation of interpersonal psychotherapy to borderline personality disorder: a comparison of combined therapy and single pharmacotherapy. Can J Psychiatry 55: 74-82.

6. Stuart S, Robertson MD (2012) Interpersonal psychotherapy: a clinician's guide. London: Hodder Arnold.

7. Gois C, Dias VV, Carmo I, Duarte R, Ferro A, et al. (2012) Treatment response in type 2 diabetes patients with major depression. Clin. Psychol Psychother 21: 39-48.

8. Monteiro IS (2011) Depressão: Por que é que uns deprimem e outros não? Lisboa: Climepsi Editores.

9. Livesley WJ (2007) Common elements of effective treatments. In: van Luyn B, Akhtar S, Livesley WJ (Eds) Severe personality disorders, Cambridge Medicine Press 211-239.

10. Baldwin RC, Anderson D, Black S, Evans S, Jones R, et al. (2003) Guideline for the management of late-life depression in primary care. Int $\mathrm{J}$ Geriatr Psychiatry 18: 829-838.

11. van Schaik DJ, Klijn AF, van Hout HP, van Marwijk HW, Beekman AT, et al. (2004) Patients' preferences in the treatment of depressive disorder in primary care. Gen Hosp Psychiatry 26: 184-189.

12. Beck AT, Steer RA, Brown GK (1996) BDI ${ }^{\circledR}$-II: Beck Depression Inventory ${ }^{\circledR}-I$ Manual. New York: Psychological Corporation.

13. Vaz Serra A, Abreu J (1973) Aferição dos quadros clínicos depressivos I - Ensaio de aplicação do inventário depressivo de beck a uma amostra portuguesa de doentes deprimidos. Coimbra Médica 20: 623-644.

14. Collins NL, Read SJ (1990) Adult attachment, working models and relationship quality in dating couples. J Pers Soc Psychol 58: 644-663.

15. Canavarro M, Dias P, Lima V (2006) Avaliação da vinculação do adulto: uma revisão crítica a propósito da aplicação da adult attachment scale-R (AAS-R) na população portuguesa. Psicologia 20: 155-186.

16. van Schaik A, van Marwijk H, Ader H, van Dyck R, de Haan M, et al. (2006) Interpersonal psychotherapy for elderly patients in primary care. Am J Geriatr Psychiatry 14: 777-786.

17. Green JD, Campbell WK (2000) Attachment and exploration in adults: chronic and contextual accessibility. Pers Soc Psychol Bull 26: 452-461.

18. Schestatsky S, Fleck M (1999) Psicoterapia das depressões. Rev Bras Psiquiatr 21.

19. Power MJ, Freeman C (2012) A randomized controlled trial of IPT versus CBT in primary care: With some cautionary notes about handling missing values in clinical trials. Clin Psychol Psychother 19: 159-169.

20. American Psychiatric Association (2002) DSM-IV-TR: Manual de diagnóstico e estatística das perturbações mentais, 4th edn. Texto revisto. Lisboa: Climepsi Editores.

21. Cuijpers $P$, Geraedts AS, van Oppen $P$, Andersson G, Markowitz JC, et al. (2011) Interpersonal psychotherapy for depression: a meta-analysis. Am J Psychiatry 168: 581-592. 